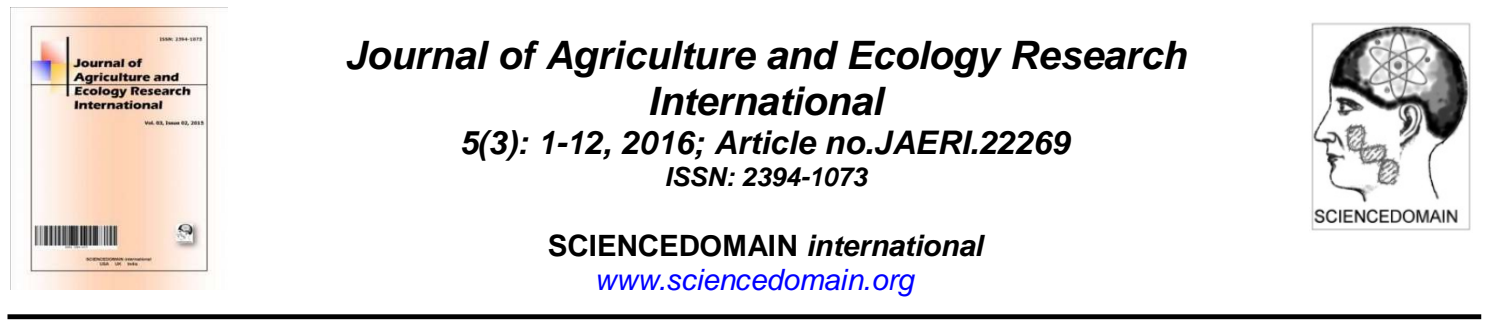

\title{
Comparison of Leaf Traits and Branching Patterns between Acacia tortilis (Forsk.) Hayne subsp. raddiana (Savi) Brenan, Balanites aegyptiaca (L.) Del. and Ziziphus mauritiana Lam. Seedlings Originated from the Sahel
}

\author{
Fidèle Tonalta Ngaryo ${ }^{1}$, Ampa-Kande Badiatte ${ }^{2}$, Venceslas Goudiaby ${ }^{3,4^{*}}$ \\ and Léonard-Élie $\mathrm{Akpo}^{2}$ \\ ${ }^{1}$ Department of Biology, University Adam Barka of Abéché, Faculty of Sciences and Technology, \\ B.P 1173, Abéché, Tchad. \\ ${ }^{2}$ Department of Crops Sciences, University Cheikh Anta Diop, Faculty of Sciences and Technology, \\ B.P 5005, Dakar, Sénégal. \\ ${ }^{3}$ Département des Sciences Biologiques, Université du Québec à Montréal, Case Postale 8888, \\ succursale Centre-ville, Montréal (Québec) H3C 3P8, Canada. \\ ${ }^{4}$ Wageningen University, Forest Ecology and Forest Management Group, P.O. Box 476700 AA \\ Wageningen, The Netherlands.
}

Authors' contributions

This work was carried out in collaboration between all authors. Author LEA designed the study, and wrote the protocol. Authors FTN and AKB conducted the measurements. Author FTN wrote the first draft of the manuscript. Authors VG and FTN managed the literature searches. Author VG performed the statistical analyses and discussed the conclusion. All authors read and approved the final manuscript.

\section{Article Information}

DOI: 10.9734/JAERI/2016/22269 Editor(s):

(1) Monica Rosa Loizzo, Department of Pharmacy, Health Sciences and Nutrition of University of Calabria, 


\section{ABSTRACT}

Aims: The aim of this study was to compare the leaf traits and branching patterns between Acacia tortilis, Balanites aegyptiaca and Ziziphus mauritiana seedlings, three species occurring in the same range in the Sahel, a semi-arid tropical area of Africa.

Study Design: Seeds used in this experiment were collected from a semi-arid area (1620'N, $\left.15^{2} 5^{\prime} \mathrm{W}\right)$, from species growing in their natural range in the Sahel. Seeds were after transferred at the experimental site where they were germinated and grown in a common garden experiment, on an area of $1300 \mathrm{~m}^{2}$.

Place and Duration of Study: The experimental site was located at around $400 \mathrm{~km}$ south of the seed origin $\left(17^{\circ} 3^{\prime} \mathrm{N}, 145^{\circ} \mathrm{W}\right)$. The experiments were carried out between October 2002 and October 2004.

Methodology: The seedlings were watered three days a week from the beginning of the experiment until July 2004. Thereafter, seedlings were assessed at 11 months, 16 months old, and at 24 months after the seed germination date. In the assessment, we measured the length $\left(L_{G U}\right)$ and the number $\left(\mathrm{N}_{\mathrm{GU}}\right)$ of growth units, the number of nodes $\left(\mathrm{N}_{\text {node }}\right)$, and leaves $\left(\mathrm{N}_{\text {leaf }}\right)$, and the single $\left(A_{\text {leaf }}\right)$ and total $\left(A_{\text {foliage }}\right)$ leaf areas.

Results: Following the water stress, $\mathrm{N}_{\text {leaf }}$ and $\mathrm{A}_{\text {leaf }}$ only decreased in $A$. tortilis, to tightly control the transpiration. $A_{\text {leaf }}$ increased in $B$. aegyptiaca and $Z$. mauritiana, due to persistent leaves flushed before the water stress. $\mathrm{A}_{\text {foliage }}, \mathrm{N}_{\mathrm{GU}}$ and $\mathrm{N}_{\text {node }}$ were generally consistent, while $\mathrm{L}_{\mathrm{GU}}$ decreased in $B$. aegyptiaca. The defoliation in dry season despite the watering suggested an endogen control, allowing the species to escape harsh conditions in their natural range.

Conclusion: The study do not support the hypothesis according to which species naturally coexisting are likely to display similar trend in leaf traits and branching patterns in response to drought. The study has been limited to three weeks of water stress and deserves to be extending to provide more insight into traits pattern for a longer period of water stress.

Keywords: Drought; growth units; leaf area; phenology; tropical area.

\section{INTRODUCTION}

The Sahel is one of the driest savanna ecozones with high inter-annual rainfall variability, ranging from 200 to $400 \mathrm{~mm}$, high potential evaporation of about $2000 \mathrm{~mm}$ year $^{-1}$ and a deep groundwater of more than $30 \mathrm{~m}$ [1]. The rainy season spans from July to September, and the dry season from October to June. The mean annual maximum temperature is between $35-37{ }^{\circ} \mathrm{C}$ with a peak up to $48^{\circ} \mathrm{C}$, and the minimum between $13-15^{\circ} \mathrm{C}$ [2]. Rainfall is one of the main limiting factors, explaining the highly variable recruitment potential generally occurring in semi-arid savannas [3]. Leaf traits are associated with resistance to drought [4] and can be used to assess species vulnerability to water shortage.

Acacia tortilis (Forsk.) Hayne, Balanites aegyptiaca (L.) Del., and Ziziphus mauritiana Lam. are multipurpose tree species naturally occurring in the Sahel, with leaf traits adapted to frequent water stress. They are used by the local population as fodder for livestock, as food and herbal medicine. The genus Acacia is particularly known to produce commercial gum, generating substantial income for local population [5]. In search for the sustainability for these species in the context of advance aridification due to climate change, there is a growing interest to better know the functional and morphological traits allowing these species to cope with drought regularly occurring in these areas. Their phenology is closely linked with climate including drought and can be used to provide insight into species response to drought.

Several studies on mature Sahelian native species [6-8] focused on qualitative phenology based on visual assessment of leafing patterns in relation with climate. Hence, $A$. tortilis is a semi-evergreen $[7,9]$, whereas $B$. aegyptiaca (L.) Del. is an evergreen species $[9,10]$. Z. mauritiana Lam. is sometimes considered as semi-evergreen [8,9], or deciduous [11]. Leaves generally flush at the end of the dry season, when the water availability at the soil surface is completely depleted for $A$. tortilis $[7,9]$, $B$. aegyptiaca [8] and Z. mauritiana [8,9]. While $A$. tortilis [7] and $Z$. mauritiana $[8,12]$ have their maximum leafing in the earlier rainy season and lasts until the middle of the dry season, $B$. aegyptiaca remains green all year round [8]. 
Water stress reduces the duration of full canopy stage for $A$. tortilis [7], while we did not find such evidence in $B$. aegyptiaca and $Z$. mauritiana. These patterns were described in mature trees and may not necessarily be translated into seedlings because the direction of the responses may be changing according to the species ontogeny. Water stress significantly reduces leaf area in $A$. tortilis seedlings [13], leaf area and leaf weight in $B$. aegyptiaca [14], and leaf area in Ziziphus sp. [15], suggesting that stress conditioning enhances adaptive traits for drought tolerance [14]. However, there are still uncertainties about the comparative traits patterns in response to drought among Acacia tortilis, $B$. aegyptiaca and Z. mauritiana. Species naturally coexisting in the same area are believed to display similar strategies to cope with water stress, which allow them to adapt to similar habitats and form the niche differentiation [16]. In this study we aimed to know the extent to which Acacia tortilis, B. aegyptiaca and Z. mauritiana differ in response to same stress.

\section{MATERIALS AND METHODS}

\subsection{Study Site, Seeds Collection and Climate}

\subsubsection{Site description}

A. tortilis, B. aegyptiaca and Z. mauritiana naturally occur in the Sahel ecozone of Senegal. Their seeds were collected near Souilène village $\left(1620^{\prime} \mathrm{N}, 15^{\circ} 5^{\prime} \mathrm{W}\right)$ located $20 \mathrm{~km}$ south of Dagana where there is a weather station that is used as reference for the zone (Fig. 1). The dry season spans from October to June, and the rainy season from July to September. Annual rainfall averages $280 \mathrm{~mm}$. The dry season can be subdivided into a hot dry season in May with average maximum and minimum temperatures of 41 and $22.8^{\circ} \mathrm{C}$ respectively, and a cool dry season in January with respective maximum and minimum temperatures of 31 and $14.8^{\circ} \mathrm{C}$ (annual average $=28.8^{\circ} \mathrm{C}$ ). The soils are sandy with a deep water table [7].

\subsubsection{Seeds collection}

The collected seeds were germinated and their seedlings transferred in the experimental site located in the Institut de Recherche pour le Développement (IRD) of Bel-Air in Dakar $17^{\circ} 33^{\prime} \mathrm{N}, 14{ }^{\circ} 5^{\prime} \mathrm{W}$, at about $400 \mathrm{~km}$ south of the seed origin (Fig. 1).
Soils of the experimental site are tropical ferruginous, non-washed [17], slightly basic $(\mathrm{pH}=8.35)$ resting on sandy sedimentary substratum, and contain $0.92 \%$ of organic matter, $0.53 \%$ of organic carbon and $0.46 \%$ of nitrogen [18]. The cold Canary current and the maritime trade winds moderate the climate [1]. Total annual rainfall is $376.3 \mathrm{~mm}$, lowest temperatures are noted in January-February $\left(20.7^{\circ} \mathrm{C}\right)$, and highest in September-October $\left(27.7^{\circ} \mathrm{C}\right)$.

\subsubsection{Climate}

In 2002, 2003, and 2004, monthly mean maximum temperatures were around $28^{\circ} \mathrm{C}$ and usually occurred in rainy season while monthly mean minimum temperatures $\left(21^{\circ} \mathrm{C}\right)$ were noted in the dry season around January and February (Fig. 3). Also, monthly mean vapor pressure displayed a minimum in the dry season $\left(18 \times 10^{-1} \mathrm{hPa}\right)$ and a peak in the rainy season $\left(30 \times 10^{-1} \mathrm{hPa}\right)$. In 2002 , total annual rainfall was $151 \mathrm{~mm}$ but the seedlings were transplanted in the late rainy season, exactly the first week of October when was recorded only $4 \mathrm{~mm}$ of rain before the end of the rainy season. In 2003 the rainy season spanned from June to October with total amount of rainfall of $385 \mathrm{~mm}$. In 2004, $234 \mathrm{~mm}$ of rainfall were recorded between June and October when dropped a last significant rain of $4 \mathrm{~mm}$. The seedlings consecutively remained almost 3 weeks without additional water.

\subsection{Experimental Design and Measurements}

In order to obtain a uniform and high germination rate, pretreatments were performed on seeds before sowing for germination. The seeds of A. tortilis were pre-treated with sulphuric acid for 60 minutes and soaking in cold water for 10 to 15 minutes. Seeds of $B$. aegyptiaca and $Z$. mauritiana seeds were pre-treated by removing the impermeable seed coats and soaking in cold water for 24 hours. In August 2002, the pretreated seeds were germinated in plastic bags filled with sand and soil mixture, at a rate of one seedling per plastic bag in a nursery located in the Centre National de Recherches Forestières (CNRF / ISRA, Dakar). The germination was followed by a nursery acclimation phase (September 2002, end of rainy season), and two months from the germination date the seedlings were transplanted in the experimental site of IRD.

The experiment was carried out in an open area of $1300 \mathrm{~m}^{2}(65 \mathrm{~m} \times 20 \mathrm{~m})$. To account for 
mortality in the course of the experiment, we planted more seedlings than we really need for the experiment (Fig. 2). All seedlings were planted at a spacing of $2 \mathrm{~m}$ by $1.3 \mathrm{~m}$ to reduce competition during the experiment $[19,20]$. In total, 96 seedlings of $A$. tortilis, 72 seedlings of $B$. aegyptiaca, and 84 seedlings of $Z$. mauritiana were planted in the experimental site (Fig. 2).

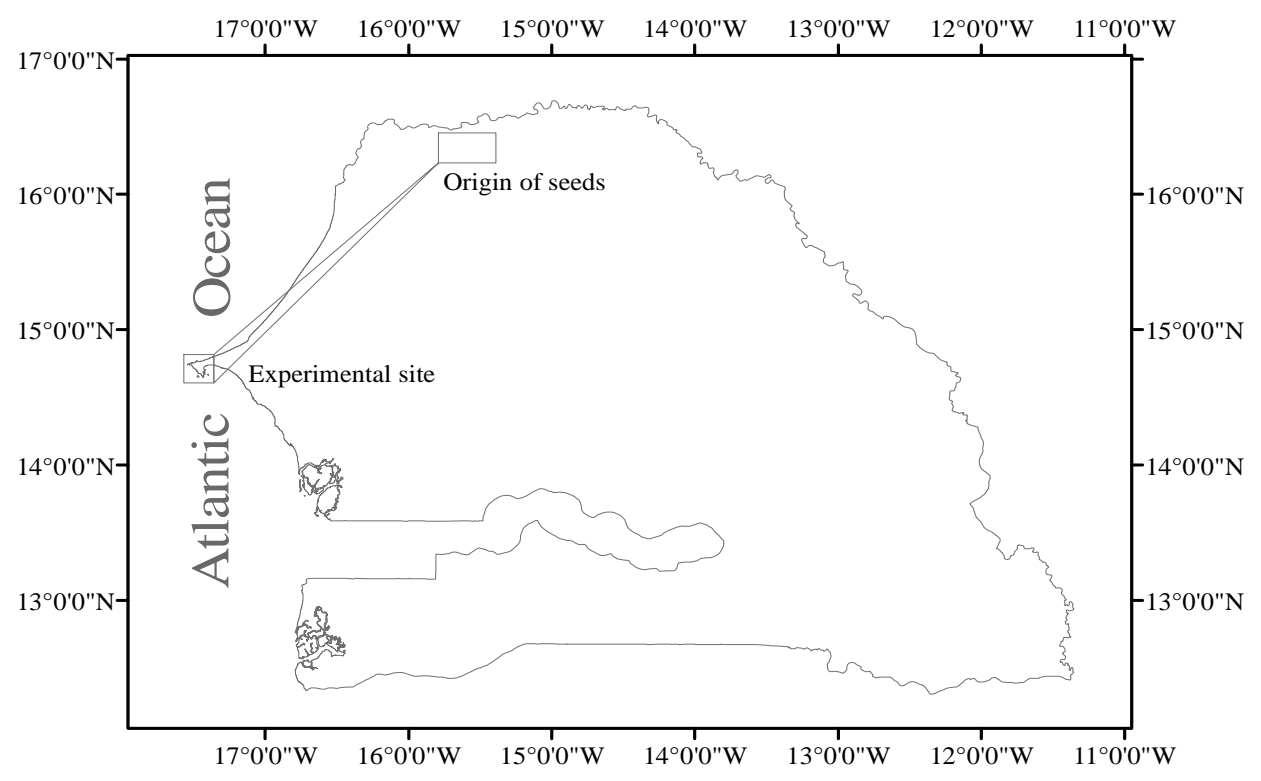

Fig. 1. Origin of the seeds of A. tortilis, B. aegyptiaca and $Z$. mauritiana from their natural stands, and location of experimental site approximately (Dakar, Senegal), $400 \mathrm{~km}$ south of the seeds origin

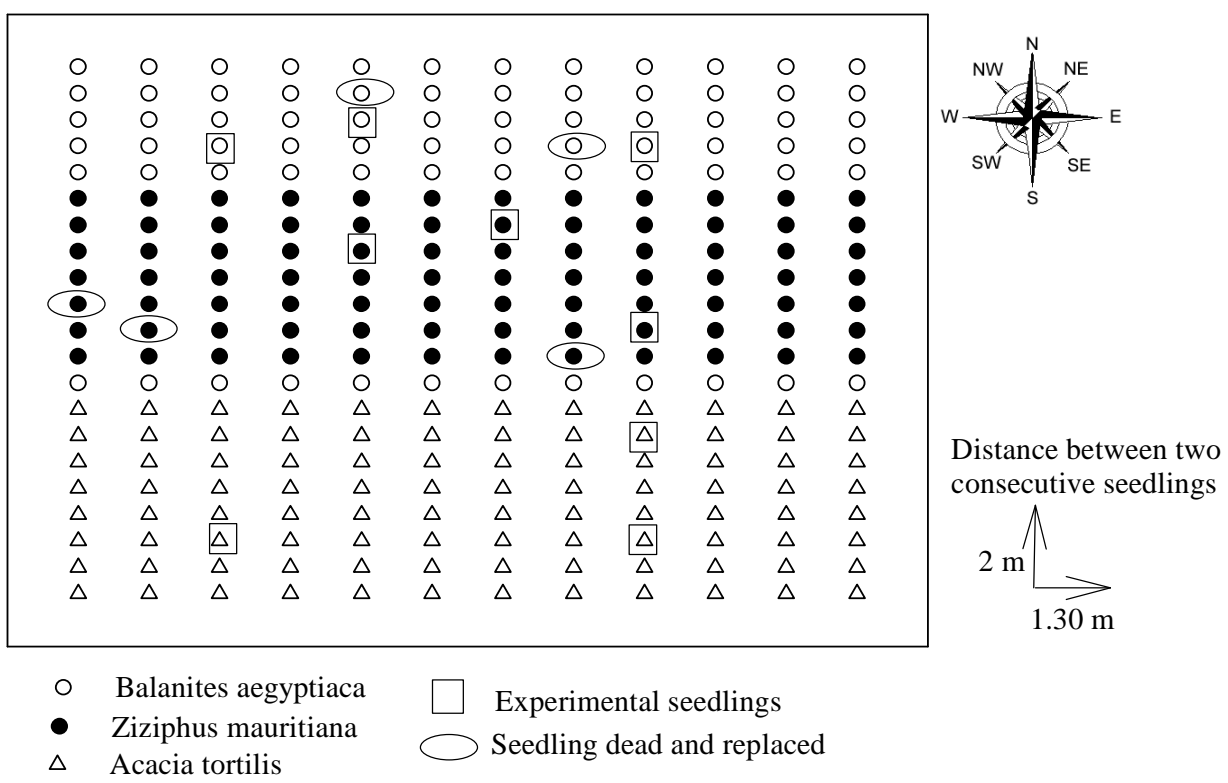

Fig. 2. Experimental design in an open area located in the Institut de Recherche pour le Développement (IRD) of Bel-Air, Dakar 1733' N, 145 5'W. Two month old seedlings of $A$. tortilis, $B$. aegyptiaca and $Z$. mauritiana were directly transplanted in the soil, after germination and acclimation in a nursery 


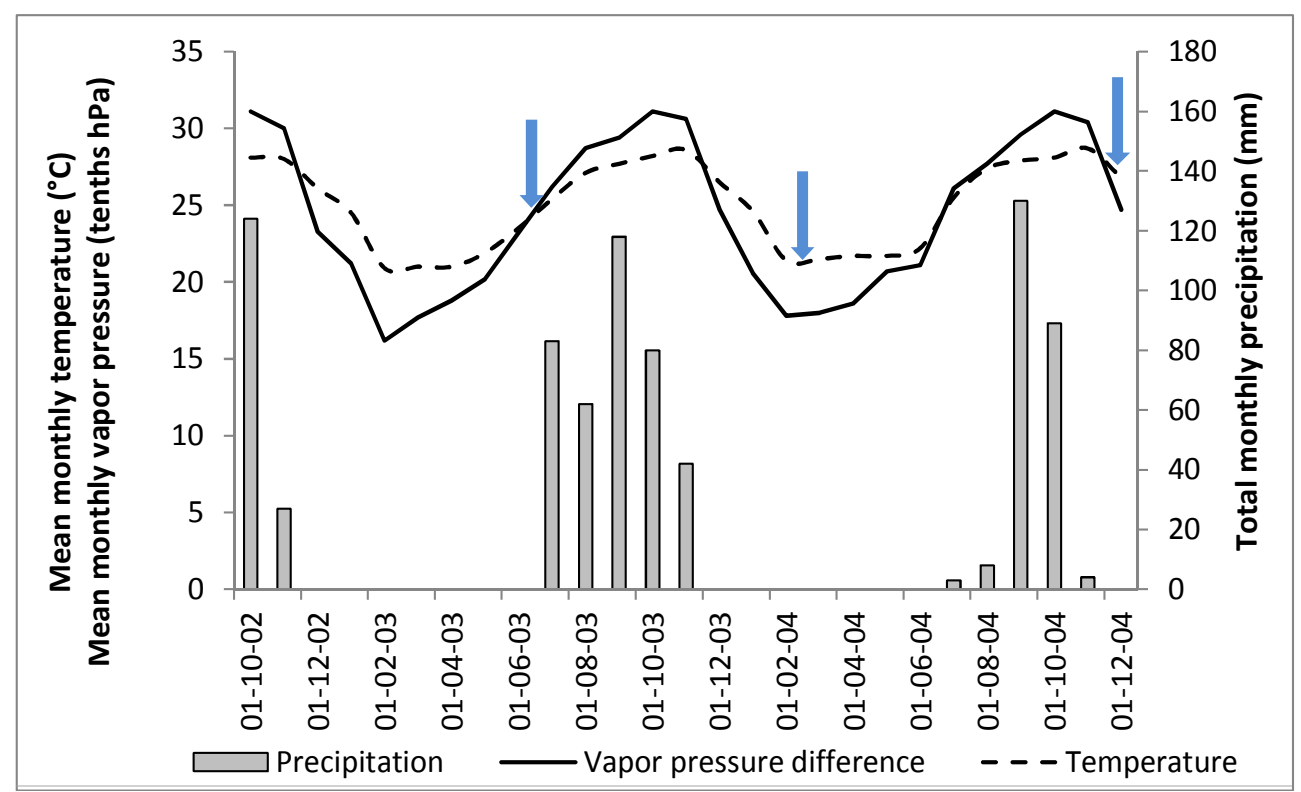

Fig. 3. Total monthly rainfall, average monthly temperature and vapor pressure of the experimental site $\left(17^{\circ} 33^{\prime} \mathrm{N}, 14^{\circ} 5^{\prime} \mathrm{W}\right)$. The reference weather station is located in Dakar-Yoff, at $12 \mathrm{~km}$ far as a crow flies from the experimental site. Data came from the monthly climatic data for the World 2002-04 (WMO-NOAA, 2002-04). The arrows indicate the measurement dates

In order to build models to estimate leaf areas, leafy twigs were destructively sampled randomly in three individuals different from the measured seedlings. The sampled twigs were stored in small refrigerated containers until they were brought to the laboratory where the projected leaf areas were measured using a leaf area meter (Model AM1, Delta-T Devices, Cambridge, UK). Linear regression models were consecutively performed then used to estimate the areas of the leaves followed in the non-destructive measurements.

On 3 month old seedlings, non-destructive measurements were carried out from October 2002 to October 2004, on 3 seedlings per species selected randomly. In tree architecture model, when an episode of continuous twig elongation is followed by an interruption of growth, it produces a morphological marker of growth interruption. A Growth Unit (GU) is the section of twig delimited by two consecutive morphological markers of growth interruption [21]. A growth unit is constituted of a succession of nodes and internodes and is defined by its order in the branching ramification pattern. Hence, along a given leafy axis, we defined a GU of order 1 as the one closer to the main stem. It bears a GU of order 2, followed by a GU of order 3 and so one, until the tip of the leafy axis. In the followed seedlings, all the different orders of growth units (GU) were numbered and marked from the top of the branches and progress downwards until the main stem. The seedlings were watered three days a week from the beginning of the experiment until July 2004 (beginning of rainy season) when the watering was withheld, making the rains the only source of water provision, until the end of the experiment at 26 months from the germination date. The seedlings were measured at three different dates. The first measurement was carried out in 11 month old seedlings $\left(\mathrm{M}_{11}\right)$, the second measurement in 16 month old $\left(\mathrm{M}_{18}\right)$, and the third one in 26 month old seedlings $\left(\mathrm{M}_{26}\right)$ (Fig 3).

In every measurement date, we counted the number of nodes and leaves of the GU. Since $B$. aegyptiaca has simple leaves and Z. mauritiana is made up only of two leaflets, the leaf length and the maximum width perpendicularly to the central rib were measured. A. tortilis has compound leaves so that number of leaflets was also counted. Single leaf area was estimated using the regression models obtained by the destructive sampling, to derive an average value for the GU. Total number of leaves and leaf area of a given seedling were obtained by adding the values of all the GU of the seedling. Total length of GU was obtained by summing up all the GU of the seedling. 


\subsection{Statistical Analyses}

A two-way analysis of variance was performed using the GLM procedure of the SAS software package version 9.3, according to the model:

$$
Y_{i j k}=\beta_{0}+\beta_{1} S_{i}+\beta_{2} G U_{i j}+\beta_{3} M_{i j k}+\beta_{4} S M_{i j k}+\varepsilon_{i j k}
$$

Where $Y$ is the dependent variable and represents the total number of leaves, average single leaf area, total leaf area, total number of $\mathrm{GU}$, total GU length, and total number of nodes per seedling. The subscripts i, j, and k represent the species, GU rank, and month respectively. The fixed effects of the model are represented by $S, G U$, and $M$ respectively for the species, GU, and month. $\beta_{0}$ is the intercept, $\beta_{1}$ to $\beta_{4}$ the estimates for the fixed effects, and $\varepsilon_{\mathrm{ijk}}$ is the error term $\left(\varepsilon_{\mathrm{ijk}} \sim \mathrm{N}\left(0 ; \sigma^{2}\right)\right)$. Interaction between $S, M$ and GU was not considered due to low replicate of GU ending with insufficient degree of freedom. An effect was considered significant at $\mathrm{P}<0.05$ based on a type III F-test on the fixed effects. When a fixed effect was significant, pairedcomparisons between species, and month were performed with a t-test $(P<0.05)$ using the LSMEANS statement and PDIFF option of SAS software.

\section{RESULTS}

\subsection{Leaf Area Estimation Models}

The linear regression models predict well the single leaf area for $A$. tortilis, B. aegyptiaca and Z. mauritiana (Table 1).

\subsection{Total Number of Leaves per Seedling}

The species $(\mathrm{F}=30.32, \mathrm{P}<0.001)$ and the month $(F=5.06, P=0.014)$ had significant effects on the total number of leaves $\left(\mathrm{N}_{\text {leaf }}\right)$ while the interaction species $\times$ month was not significant (Table 2).

For $A$. tortilis, $\mathrm{N}_{\text {leat }}$ were 96,66 and 63 in $\mathrm{M}_{11}, \mathrm{M}_{18}$ and $\mathrm{M}_{26}$, respectively (Fig. 4). Significantly lower $N_{\text {leaf }}$ were noted in $M_{18} \quad(P=0.05)$ and $M_{26}$ $(P=0.03)$ relatively to $M_{11}$, while no difference was noted between $M_{18}$ and $M_{26}$. For $B$. aegyptiaca and $Z$. mauritiana $\mathrm{N}_{\text {leaf }}$ hardly varied for the duration of the experiment. A. tortilis had all the time significantly higher $\mathrm{N}_{\text {leaf }}$ than $B$. aegyptiaca $(P<0.001)$ and $Z$. mauritiana
$(\mathrm{P}<0.001)$. The water stress reduced $\mathrm{N}_{\text {leat }}$ by $5 \%$ in $A$. tortilis and $83 \%$ in B. aegyptiaca, whereas an increase of $62 \%$ was noted in $Z$. mauritiana.

\subsection{Average Single Leaf Area}

The species, the month and the interaction between species and month had significant effects on the average single leaf area $\left(A_{\text {leaf }}\right)$ as shown in Table 2. A. tortilis displayed a quite constant $A_{\text {leaf }}$ of about $0.31 \mathrm{~cm}^{2}$ in average over the three measurement dates (Fig. 4). For $B$. aegyptiaca, $A_{\text {leaf }}$ were $0.56,1.38$ and 1.72 for $M_{11 \text { wet }}, M_{18 \text { wet }}$ and $M_{26}$, respectively. Relatively to $\bar{M}_{11 \text { wet }}$, significant increase of $A_{\text {leaf }}$ was noted in $M_{26}, \quad(P=0.008)$, but no difference was observed between $M_{18 \text { wet }}$ and $M_{26}$. For Z. mauritiana, $A_{\text {leaf }}$ were $0.30,0.33$ and 2.29 for $M_{11}, M_{18}$ and $M_{26}$, respectively. In $M_{2}, A_{\text {leaf }}$ significant increased relatively to both $M_{11}$ $(P<0.001)$ and $M_{18}(P<0.001)$. The three species showed similar $A_{\text {leaf }}$ in $M_{11}$. In $M_{18}$, only $A$. tortilis displayed significantly lower $A_{\text {leaf }}$ than B. aegyptiaca $(P=0.031)$.

\subsection{Total Leaf Area of Seedlings}

Only the month had a significant effect (Table 2) on the total seedling leaf area $\left(A_{\text {foliage }}\right)$. The average $A_{\text {foliage }}$ were respectively 26.92 and $28.24 \mathrm{~cm}^{2}$ in $A$. tortilis and $B$. aegyptiaca, with no significant fluctuations over the three measurement dates (Fig. 4). For Z. mauritiana, $A_{\text {foliage }}$ were 9.05, 2.21 and 74.57, in $\mathrm{M}_{11}, \mathrm{M}_{18}$ and $M_{26}$, respectively. A significant increase was noted in $\mathrm{M}_{26}$ relatively to $\mathrm{M}_{11}(P=0.013)$. Overall, $A_{\text {foliage }}$ did not significantly vary between species.

\subsection{Total Number of Growth Units per Seedling}

Growth units differed significantly among species (Table 2). Total number of growth units $\left(\mathrm{N}_{\mathrm{GU}}\right)$ slightly decreased in $A$. tortilis and increased in $B$. aegyptiaca, and $Z$. mauritiana, but the effects of water stress were not significant. $N_{\mathrm{GU}}$ had average values of 10 in $A$. tortilis, 21 in $B$. aegyptiaca, and 14 in $Z$. mauritiana. The three species showed no significant difference in $M_{11}$. Following the water stress, $A$. tortilis had significantly lower $\mathrm{N}_{\mathrm{GU}}$ than $B$. aegyptiaca $(P=0.005)$ and $Z$. mauritiana $(P=0.037)$, while all other differences between species were insignificant. 


\subsection{Total Length of Growth Unit per Seedling}

The species, GU, and month had significant effects (Table 2) on the total length of $G U\left(L_{G U}\right)$. $\mathrm{L}_{\mathrm{GU}}$ was in average $21.67 \mathrm{~cm}$ in $A$. tortilis with no significant variations (Fig. 5). For $B$. aegyptiaca, $L_{G U}$ were 25,79 , and 47 in $M_{11}, M_{18}$ and $M_{26}$, respectively. $L_{G U}$ significantly increased from $M_{11}$ to $M_{18}(P<0.001)$, and decreased from $M_{18}$ to $M_{26}$ $(P=0.024)$. For $Z$. mauritiana, $L_{G U}$ were 9,54 , and 26 for $M_{11}, M_{18}$ and $M_{26}$, respectively. $A$ significant increase was noted between $M_{11}$, and $M_{18}(P=0.005)$. In $M_{11}, L_{G U}$ did not vary between the three species. However, $A$. tortilis had significantly shorter $\mathrm{GU}$ than $B$. aegyptiaca in both $\mathrm{M}_{18}(\mathrm{P}=0.004)$ and $\mathrm{M}_{26}(\mathrm{P}=0.04)$.

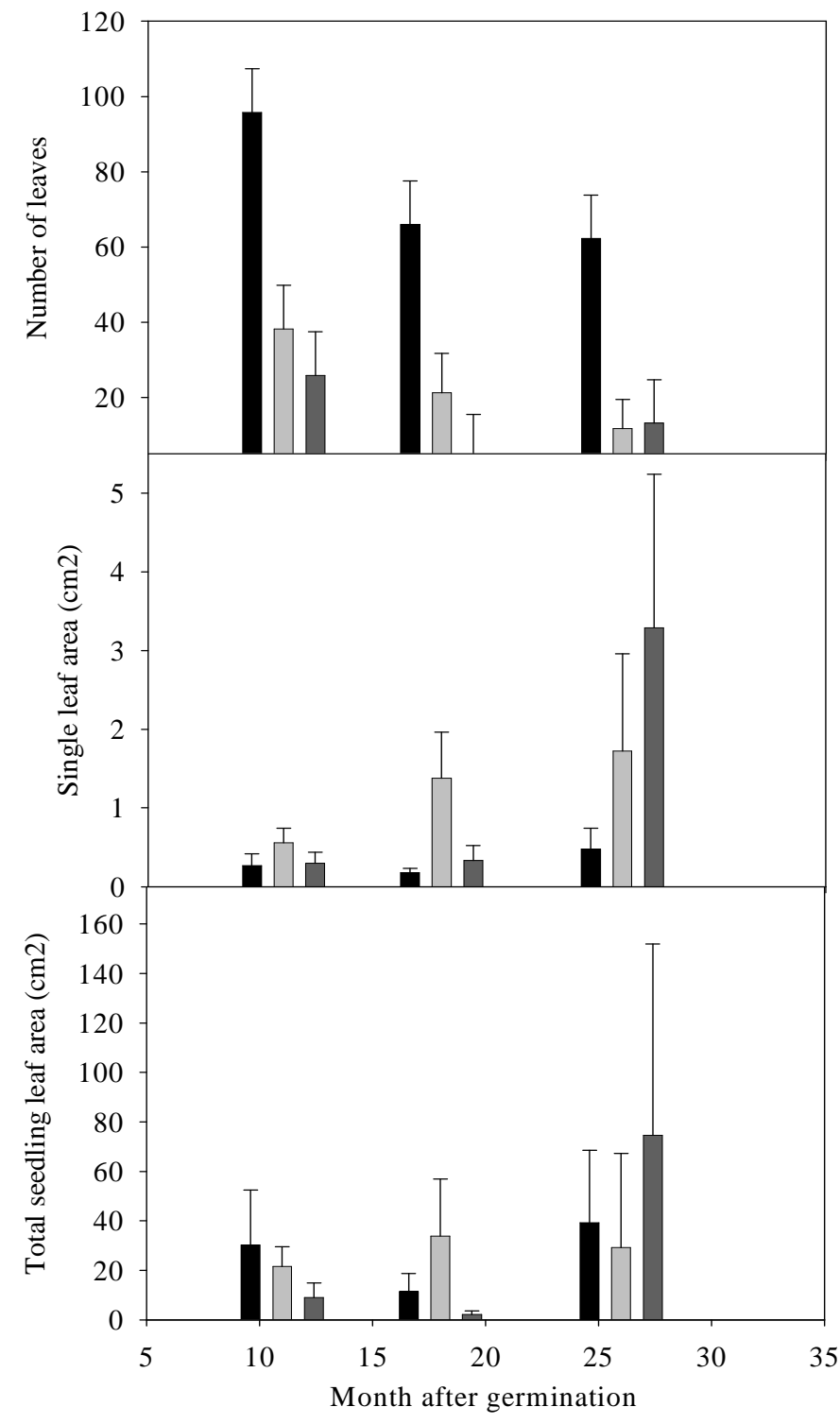

Acacia tortilis Balanites aegyptiaca

Ziziphus mauritiana

Fig. 4. Number of leaves, single leaf area, and total leaf area followed on seedlings from their germination to 26 month old in A. tortilis, $Z$. mauritiana, and B. aegyptiaca in a semi-controlled experiment. Seedlings were watered from the start of the experiment until month 23; when the watering was withheld at the beginning of the rainy season until month 26 . Error bars represent standard errors 
Table 1. Linear model of assessment of the single leaf area $\left(A_{\text {leaf }}, \mathrm{cm}^{2}\right)$ of 24 month old seedlings of $A$. tortilis, $B$. aegyptiaca and $Z$. mauritiana

\begin{tabular}{|c|c|c|c|c|}
\hline Species & Prediction model of $A_{\text {leaf }}$ & $\mathbf{N}$ & $\mathbf{R}^{2}$ & $\mathbf{P}$ \\
\hline A. tortilis & $0.164 \times\left(L_{\text {leafstalk }}\right)+0.164 \times\left(\mathrm{N}_{\text {leaflet }}\right)-0.523$ & 228 & 0.61 & $P<0.001$ \\
\hline B. aegyptiaca & $1.040 \times\left(\mathrm{L}_{\text {leaf }}\right)+1.999 \times\left(\mathrm{W}_{\text {leaf }}\right)-4.639$ & 109 & 0.84 & $P<0.001$ \\
\hline Z. mauritiana & $1.493 \times\left(L_{\text {leaf }}\right)+3.437 \times\left(W_{\text {leat }}\right)-5.759$ & 130 & 0.96 & $P<0.001$ \\
\hline
\end{tabular}

Table 2. Two-way ANOVA of the effects of Species, GU rank, month and the interactions Species $\times$ Month on the leaf and growth unit traits in a semi-controlled experiment on seedlings of $A$. tortilis, B. aegyptiaca and $Z$. mauritiana

\begin{tabular}{|c|c|c|c|c|c|}
\hline Source & df & Anova SS & Mean square & F value & $P>F$ \\
\hline \multicolumn{6}{|c|}{ Number of leaves per seeding } \\
\hline Species & 2 & 25610.40 & 12805.20 & 30.32 & $<0.001$ \\
\hline GU rank & 6 & 2770.94 & 461.82 & 1.09 & 0.392 \\
\hline Month & 2 & 4174.05 & 2087.02 & 4.94 & 0.015 \\
\hline Species $\times$ Month & 4 & 668.57 & 167.14 & 0.40 & 0.810 \\
\hline \multicolumn{6}{|c|}{ Average single leaf area } \\
\hline Species & 2 & 9.10 & 4.55 & 6.38 & 0.006 \\
\hline GU rank & 6 & 4.11 & 0.68 & 0.96 & 0.471 \\
\hline Month & 2 & 18.05 & 9.02 & 12.65 & $<0.001$ \\
\hline Species $\times$ Month & 4 & 11.69 & 2.92 & 4.10 & 0.011 \\
\hline \multicolumn{6}{|c|}{ Total leaf area per seedling } \\
\hline Species & 2 & 215.40 & 107.70 & 0.09 & 0.911 \\
\hline GU rank & 6 & 3050.17 & 508.36 & 0.44 & 0.848 \\
\hline Month & 2 & 8655.11 & 4327.55 & 3.72 & 0.038 \\
\hline Species $\times$ Month & 4 & 6663.05 & 1665.76 & 1.43 & 0.252 \\
\hline \multicolumn{6}{|c|}{ Total number of growth units per seedling } \\
\hline Species & 2 & 772.76 & 386.38 & 3.87 & 0.0313 \\
\hline GU rank & 6 & 8737.37 & 1456.23 & 14.58 & $<0.001$ \\
\hline Month & 2 & 35.55 & 17.77 & 0.18 & 0.838 \\
\hline Species $\times$ Month & 4 & 675.04 & 168.76 & 1.69 & 0.177 \\
\hline \multicolumn{6}{|c|}{ Total length of growth units per seedling } \\
\hline Species & 2 & 6968.01 & 3484.01 & 6.53 & 0.004 \\
\hline GU rank & 6 & 51363.02 & 8560.50 & 16.05 & $<0.001$ \\
\hline Month & 2 & 12193.38 & 6096.69 & 11.43 & $<0.001$ \\
\hline Species $\times$ Month & 4 & 1176.29 & 294.07 & 0.55 & 0.700 \\
\hline \multicolumn{6}{|c|}{ Total number of nodes per seedling } \\
\hline Species & 2 & 2058.50 & 1029.25 & 12.03 & $<0.001$ \\
\hline GU rank & 6 & 14840.63 & 2473.44 & 28.92 & $<0.001$ \\
\hline Month & 2 & 3300.21 & 1650.11 & 19.29 & $<0.001$ \\
\hline Species $\times$ Month & 4 & 194.56 & 48.64 & 0.57 & 0.688 \\
\hline
\end{tabular}

\subsection{Total Number of Nodes per Seedling}

Significant effects of species, GU and month were noted in the number of nodes $\left(\mathrm{N}_{\text {node }}\right)$. For $A$. tortilis, $\mathrm{N}_{\text {node }}$ were 25, 43 and 44 in $\mathrm{M}_{11}, \mathrm{M}_{18}$ and $\mathrm{M}_{26}$, respectively (Fig. 5), with a significant positive shift in $M_{18} \quad(P=0.019)$ and $M_{26}$
$(P=0.01)$ compared to $M_{11}$. B. aegyptiaca had 6, 36 and 36 nodes in $M_{11}, M_{18}$ and $M_{26}$, with significant increase in $M_{18} \quad(P<0.001)$ and $M_{26}$ $(P<0.001)$ relatively to $M_{11}$. For $Z$. mauritiana, $N_{\text {node }}$ were 7,25 , and 26 in $M_{11}, M_{18}$ and $M_{26}$, respectively. However, relatively to $M_{11}, N_{\text {node }}$ significantly increased in $M_{18}(P<0.008)$ and $M_{26}$ 
$(\mathrm{P}<0.006)$. A. tortilis had significantly lower $\mathrm{N}_{\text {node }}$ than $B$. aegyptiaca $(P=0.05)$ in M18. Following the water stress, $A$. tortilis showed significantly lower $\mathrm{N}_{\text {node }}$ compared to $B$. aegyptiaca $(P=0.005)$ and $Z$. mauritiana $(P=0.037)$.

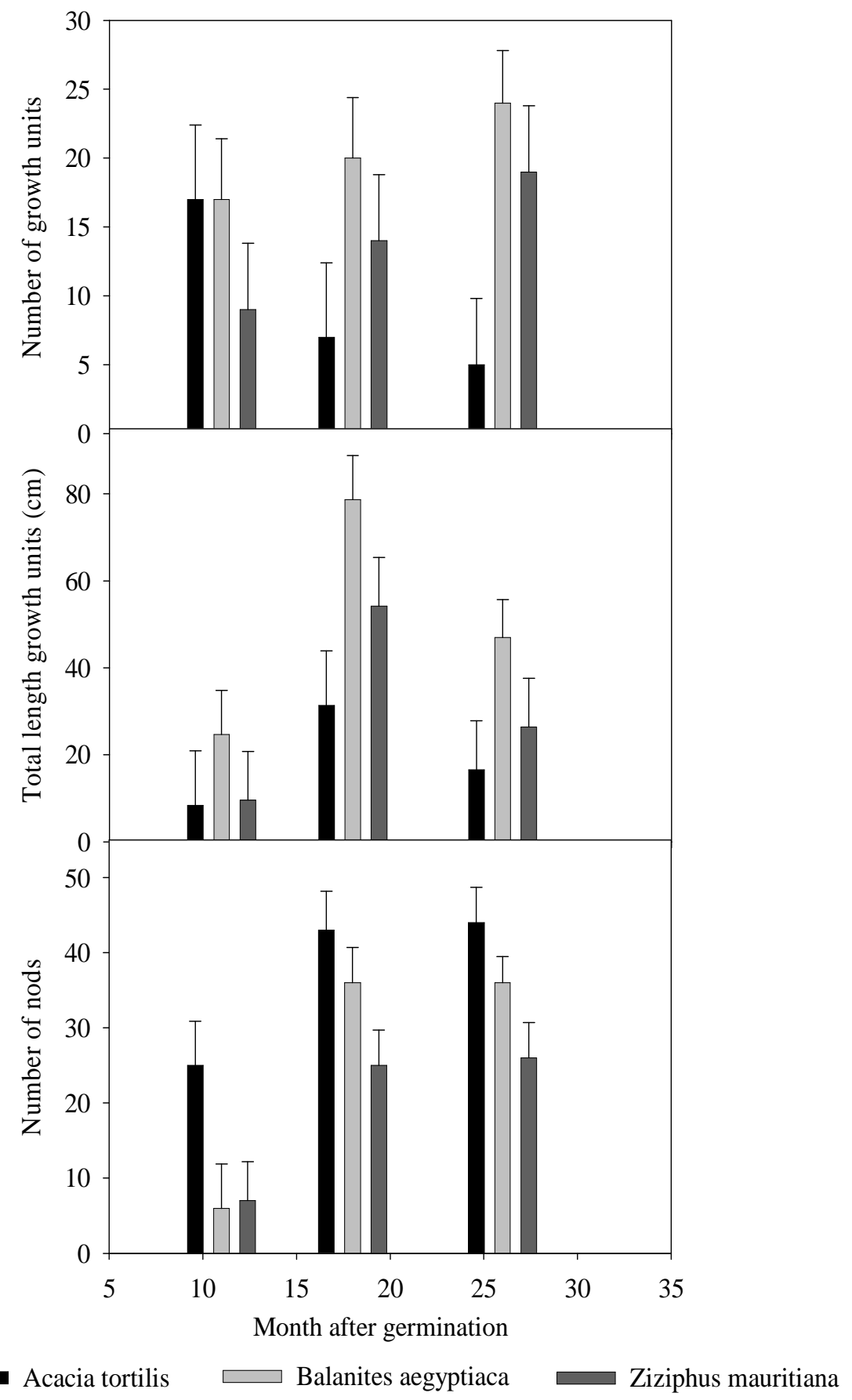

Fig. 5. Number of growth units, their total length, and the number of nodes followed on seedlings from their germination to 26 month old in A. tortilis, $Z$. mauritiana, and B. aegyptiaca in a semi-controlled experiment. Seedlings were watered from the start of the experiment until month 23; when the watering was withheld before the rainy season until month 26 . Error bars represent standard errors 


\section{DISCUSSION}

This study aimed to compare leaf traits and branching patterns between $A$. tortilis, $B$. aegyptiaca and $Z$. mauritiana seedlings, three species naturally occurring in the same area. Two main information can be drawn from this study. The first one pertains to the patterns displayed within one species, and the second one lays on the difference between species in their response to drought.

\subsection{Variation within Species}

Despite the favorable soil water status due to the watering, all the species shed their leaves, even slightly, in the dry season, but not translating into total leaf area reduction. In their natural range, a systematic defoliation also occurs in hot dry season for $A$. tortilis [7], and $Z$. mauritiana [9]. $B$. aegyptiaca also shed its leaves in hot dry season but defoliation overlaps with the next leaf flush [9]. In addition, a systematic defoliation of A. tortilis, grown in the Negev where it was introduced, occurs when soil water status is locally favorable, corresponding to the hot dry season of their origin in Africa [22]. The defoliation at least for $A$. tortilis may therefore be related to an endogen control, and the same mechanism may have played for $B$. aegyptiaca and $Z$. mauritiana, as well. In their natural range where drought is real at this time of the year, this could be seen as an escape strategy because maintaining lower foliage in hot dry season is conducive to some extent to tight regulation of leaf transpiration. Hence, soil water availability is seldom, if ever, to be the only variable explaining leaf shading in dry season.

$B$. aegyptiaca and $Z$. mauritiana increased their growth unit lengths in the middle of the dry season in response to favorable soil water availability while $A$. tortilis showed a stronger seasonality of its GU elongation. This also indicates that $B$. aegyptiaca and $Z$. mauritiana elongate their twigs in dry season to be able to respond to soil water experimentally increased in this period. Following the water stress, the GU length only decreased for $B$. aegyptiaca suggesting the active phase of GU elongation in dry season and the plastic behavior to water stress of this species. Based on GU patterns, Z. mauritiana displayed higher tolerance to stress as shown by its consistent GU elongation despite water stress. The greater number of $\mathrm{GU}$ and nodes in $A$. tortilis consecutively to water stress resulted in reduced internode distances, ending up with a greater number of nodes per unit of leafy axis. The study illustrates the statement according to which, measurement of shoot or twig is an effective way to assess fine scale plant response to environmental stimuli [23].

\subsection{Variation between Species}

The water stress was followed by a marked decrease in single leaf area for $A$. tortilis, but an increase for $B$. aegyptiaca and $Z$. mauritiana, however not resulting in significant variation in total leaf area. However, the slight defoliation generally observed, was enough to maintain a consistent total leaf area despite the significant change in single leaf area in the three species. A. tortilis had generally more leaves than $B$. aegyptiaca and Z. mauritiana all the time, even before the stress was applied. Earlier studies have reported leaf area decrease due to water stress in A. tortilis [13], B. aegyptiaca [24] and Ziziphus [15]. Water stress has been shown to reduce leaf area through reduced leaf initiation, leaf size and leaf production rate [13]. We also observed in $A$. tortilis a reduced leaf production rate, even if it was not significant. The advantage of having higher number of leaves associated with lower size single leaf areas is to allow more plasticity in leaf surface area regulation. Small leaves ensure for convective heat loss that improves cooling in hot, dry conditions, and a tight control of transpiration [25].

Unexpectedly, Z. mauritiana had greater single leaf areas following the water stress. $B$. aegyptiaca also positively reacted to water stress, but in comparison with first measurement date and not the second. The greater single leaf area can be explained by the fact that leaves earlier flushed when the trees were not stressed still persisted when the water stress occurred. To be able to increase their single leaf area while maintaining a consistent total leaf area following the water stress, $B$. aegyptiaca and Z. mauritiana, have to shed proportionally their leaves to balance their single leaf area increase. After the rainy season of 2004 with $234 \mathrm{~mm}$ of rainfall, the seedlings remained 3 weeks without additional water in soil. $B$. aegyptiaca and Z. mauritiana may have kept their leaves flushed during this previous rainy season or sooner while the seedlings were still watered. Three weeks of water stress seemed to be too short for $B$. aegyptiaca and $Z$. mauritiana to shed their leaves, showing that they can withstand water stress, longer than $A$. tortilis. 


\subsection{What can we Learn so Far?}

A. tortilis, B. aegyptiaca and $Z$. mauritiana naturally occur in the same range characterized by harsh climate conditions with frequent drought episodes. They have sclerophillous leaves and can withstand severe water stress. Two clear patterns emerge from this study. A. tortilis bears more leaves which are also smaller than those of their counterparts, as a strategy to cope with soil water depletion. B. aegyptiaca and Z. mauritiana withstand water stress by keeping larger single leaf area, because they might have kept their greater size leaves flushed whether during the previous rainy season or earlier when the seedlings were still watered. In addition, $B$. aegyptiaca decreased its GU length following the water stress. Overall, larger plasticity in response to drought was observed in $A$. tortilis compared to $B$. aegyptiaca and $Z$. mauritiana. In addition, within a given species, the same seedlings were followed during the course of the experiment, at different ages. However it is unlikely that the age of the seedlings influenced the leaf size, since individual leaf area was shown to have a modest increase with plant size [26]. In a typical common garden experiment, many provenances are grown in a common area to study the phenotypic variability. In our experiment, the seeds which have been germinated were rather collected in a restricted area where the species naturally coexist. The differences in leaf traits and branching patterns may therefore not be attributed to a genetic variability leading to a phenotypic divergence within the species.

\section{CONCLUSION}

In the Sahel, a semi-arid tropical area of Africa where we collected the geminated seeds used in this experiment, soil water availability is the main environmental driving factor. $A$. tortilis, $B$. aegyptiaca and $Z$. mauritiana naturally coexist in these areas and the understanding of how they cope with water shortage is essential to implement guidelines for a more efficient assisted recruitment. This study provides to these purposes important information on leaf traits and branching patterns related to soil water availability. In contrast with what we hypothesized, species naturally coexisting do not necessarily displayed similar trend in leaf traits and branching patterns in response to drought. Although straightforward, the study was limited to three weeks of water stress. Perspectives for future studies suggest extending the drought period.

\section{ACKNOWLEDGEMENTS}

Project administration and funding were provided by Université Cheikh Anta Diop, Dakar, Senegal. The research was conducted in the Laboratory of plant ecology of the Institut de Recherche pour le Development (IRD).

\section{COMPETING INTERESTS}

Authors have declared that no competing interests exist.

\section{REFERENCES}

1. Le Houérou HN. Definition, geographical limits, contacts with other ecoclimatic zones. In: The grazing land ecosystems of the African Sahel, Springer Berlin Heidelberg; 1989.

2. Lawesson JE. Sahelian woody vegetation in Senegal. Vegetatio. 1990;86:161-174.

3. Couteron P, Kokou K. Woody vegetation spatial patterns in a semi-arid savanna of Burkina Faso, West Africa. Plant Ecol. 1997;132(2):211-227.

4. Deines JM, Hellmann JJ, Curran TJ. Traits associated with drought survival in three Australian tropical rainforest seedlings. Aust. J. Bot. 2011;59(7):621-629.

5. Ngaryo FT, Goudiaby VA, Dagbenonbakin GD, Agbangba EC, Diatta S, Akpo LE. Modeling the production of Arabic gum (Acacia senegal (L.) Willd) based on the proper tapping characteristics in the semi arid Sahel of Chad. International Journal of Science and Advanced Technology. 2011; 1(8):24-30.

6. Grouzis M, Sicot M. A method for the phenological study of browse populations in the Sahel: The influence of some ecological factors. In: Browse in Africa, the current state of knowledge, Le Houérou éd. ILCA, Addis Abeba; 1980.

7. Do FC, Goudiaby VA, Gimenez O, Diagne AL. Diouf $M$, Rocheteau $R$, Akpo LE. Environmental influence on canopy phenology in the dry tropics. Forest Ecol. Manag. 2005;215:319-328.

8. De Bie S, Ketner P, Paasse M, Geerling C. Woody plant phenology in the West Africa savanna. J. Biogeogr. 1998;25(5):883-900.

9. Seghieri J, Do CF, Devineau JL, Fournier A. Phenology of woody species along the climatic gradient in West Tropical Africa. In: Phenology and Climate Change, Dr. Xiaoyang Zhang (Ed.), In Tech; 2012. 
10. Akpo LE. Phenological interactions between tree and understory herbaceous vegetation of a sahelian semi-arid savanna. Plant Ecol. 1997;131(2):241-248.

11. Mishra RK, Upadhyay VP, Bal S, Mohapatra PK, Mohanty RC. Phenology of species of moist deciduous forest sites of Similipal biosphere reserve. Lyonia. 2006; 11(1):5-17.

12. Grice C. Ecology in the management of Indian Jujube (Ziziphus mauritiana). Weed Science. 1998;46(4):467-474.

13. Otieno DO, Schmidt MWT, Adiku S, Tenhunen J. Physiological and morphological responses to water stress in two Acacia species from contrasting habitats. Tree Physiol. 2005;25(3): 361-371.

14. Elfeel AA, Warrag El, Musnad HA. Response of Balanites aegyptiaca (L.) Del. seedlings from varied geographical source to imposed drought stress. Discov. Innov. 2007;184:319-325.

15. Arndt SK, Clifford SC, Wanek W, Jones HG, Popp M. Physiological and morphological adaptations of the fruit tree Ziziphus rotundifolia in response to progressive drought stress. Tree Physiol. 2001;21(11):705-715.

16. Xu F, Guo W, Xu W, Wei Y, Wang R. Leaf morphology correlates with water and light availability: What consequences for simple and compound leaves? Prog. Nat. Sci. 2009;19(12):1789-1798.

17. Diagne $Y$. Boisements et paysages dans la ville de Dakar. Mémoire de maîtrise, UCAD, FLSH, Dakar; 1988. French.

18. Ngaryo FT, Akpo LE, Goudiaby, VA, Badiatte AK, Logbo J, Diouf M. Estimation de la surface foliaire de jeunes plants de trois essences sahéliennes: Acacia tortilis, Balanites aegyptiaca et Ziziphus mauritiana en conditions semi naturelles (Dakar, Sénégal). Annales de l'Université de N'Djaména. Série C N2:27-41. French; 2007.

19. Goudiaby V, Brais S, Grenier Y, Berninger $F$. Thinning effects on jack pine and black spruce photosynthesis in Eastern boreal forests of Canada. Silva Fennica. 2011; 45(4):595-609.

20. Goudiaby V, Brais S, Berninger F, Schneider R. Vertical patterns in specific volume increment along stems of dominant jack pine (Pinus banksiana) and black spruce (Picea mariana) after thinning. Can. J. For. Res. 2012;42(4):733-748.

21. Barthélémy $D$, Caraglio $Y$. Plant architecture: A dynamic, multilevel and comprehensive approach to plant form, structure and ontogeny. Ann. Bot. 2007; 99:375-407.

22. Halevy G, Orshan G. Ecological studies on Acacia species in the Negev and Sinai. II. Phenology of Acacia raddiana, A. tortilis and $A$. gerrardii negevensis. Israël J. Bot. 1973;22:120-138.

23. Naydenov K, Tremblay $F$, Bergeron $\mathrm{Y}$, Goudiaby V. Effect of active charcoal on the primary growth of jack pine seedlings, Influence du charbon actif sur la croissance primaire des plantules de pin gris. Can. J. For. Res. 2006;36(3):761-767.

24. Elfeel A, Warrag E, Musnad H. Response of Balanites aegyptiaca (L.) Del. seedlings from varied geographical source to imposed drought stress. Discov. Innov. 2007;184:319-325.

25. Yates MJ, Anthony Verboom G, Rebelo AG, Cramer MD. Ecophysiological significance of leaf size variation in Proteaceae from the Cape Floristic Region. Funct. Ecol. 2010;24(3):485-492.

26. Price CA, Wright IJ, Ackerly DD, Niinemets $U$, Reich PB, Veneklaas EJ. Are leaf functional traits 'invariant' with plant size and what is 'invariance' anyway? Funct. Ecol. 2014;1-14.

(0) 2016 Ngaryo et al.; This is an Open Access article distributed under the terms of the Creative Commons Attribution License (http://creativecommons.org/licenses/by/4.0), which permits unrestricted use, distribution, and reproduction in any medium, provided the original work is properly cited.

Peer-review history:

The peer review history for this paper can be accessed here: http://sciencedomain.org/review-history/12256 